\title{
Effects of transportation stress on quality and sensory profiles of Nile
} \section{tilapia fillets}

\author{
Elenice Souza dos Reis Goes ${ }^{1 *}$, Jorge Antônio Ferreira de Lara², Eliane Gasparino ${ }^{3}$, Marcio Douglas Goes ${ }^{4}$, Jovana Silva Garbelini \\ Zuanazzi ${ }^{5}$, Nelson Maurício Lopera-Barrero ${ }^{6}$, Maria del Pilar Rodriguez Rodriguez ${ }^{3}$, Pedro Luiz de Castro ${ }^{3}$, Ricardo Pereira Ribeiro ${ }^{3}$
}

${ }^{1}$ Federal University of Grande Dourados/Faculty of Agricultural Sciences, Rod. Dourados/ttahum, km 12 79804-970 - Dourados, MS - Brazil.

${ }^{2}$ Embrapa Pantanal, R. 21 de Setembro, 1880 - 79320-900

- Corumbá, MS - Brazil.

${ }^{3}$ State University of Maringá - Dept. of Animal Science, Av. Colombo, 5790 - 87020-900 - Maringá, PR - Brazil.

${ }^{4}$ Western Paraná State University - Dept. of Animal Science, R. Pernambuco, 1777 - 85960-000 - Marechal Cândido

Rondon, PR - Brazil.

${ }^{5}$ State University of Maringá - Dept. of Food Science.

${ }^{6}$ State University of Londrina - Dept. of Animal Science, Rod. Celso Garcia Cid, km 380, s/n - 86057-970 - Londrina, PR - Brazil.

*Corresponding author <elenicesreis@yahoo.com.br>

Edited by: Gerson Barreto Mourão

Received September 22, 2016

Accepted May 17, 2017
ABSTRACT: This study evaluated pre-slaughter stress and its influence on the stress indicators, quality characteristics and sensory characteristics of Nile tilapia fillets. To this end, two experiments were conducted: (1) two transportation times (60 and $240 \mathrm{~min}$ ), with a density of 200 $\mathrm{kg} \mathrm{m}^{-3}$, were compared to control treatment fish (in which the fish were removed from the net cage and immediately euthanized); and (2) two transportation densities (100 and $400 \mathrm{~kg} \mathrm{~m}^{-3}$ ), transported for 180 min, compared with control treatment fish. In experiment 1 , the transportation time of 60 min resulted in higher levels of serum cortisol and plasma glucose compared to the transportation time of $240 \mathrm{~min}$ and the control. Fish fillets transported for $240 \mathrm{~min}$ had higher water-holding capacity, less water loss by pressure and higher levels of juiciness compared to fish transported for $60 \mathrm{~min}$. Color, $\mathrm{pH}$ and water loss during cooking were not affected by transportation time. In experiment 2, transportation densities of 100 and $400 \mathrm{~kg} \mathrm{~m}^{-3}$ did not significantly affect the stress indicators nor the instrumental quality parameters of the fillets, but fish transported at $400 \mathrm{~kg} \mathrm{~m}^{-3}$ showed better visual acceptance by panellists.

Keywords: Oreochromis niloticus, $\mathrm{pH}$, colorimetry, water holding capacity, sensory analysis

\section{Introduction}

Pre-slaughter stress is an important issue for the industry, as it directly influences the welfare and meat quality of animals. Studies of fish have shown that pre-slaughter stress affects the color, texture and water loss of the meat (Stien et al., 2005; Sveinsdóttir et al., 2010; Rahmanifarah et al., 2011; Digre et al., 2011; Goes et al., 2015). The mechanisms that explain these changes in meat quality are related to the depletion of stores of glycogen and muscle adenosine triphosphate (ATP) with an increase in anaerobic glycolysis due to excessive exercise during stress. One of the metabolites resulting from anaerobic activity is lactic acid, which accumulates in muscle and causes a drop in muscle $\mathrm{pH}$ (Barton, 2002).

This low pH may account for changes in the quality of the meat because it leads to the early onset of rigor mortis (Bahuaud et al., 2010; Roth et al., 2012) and structural breakdown with higher proteolytic activity (Hultman et al., 2012). The mechanical stress on muscle fibers or connective tissue, which causes the release of proteases, may also contribute to the acceleration of the post-mortem softening of the flesh (Roth et al., 2006). Furthermore, the reduction in water-holding capacity may be related to structural alterations in fish muscle (detachment of the sarcolemma, gaps in the extracellular matrix, widening of the intermyofibrillar space and transversal shrinkage of the cells) (Olsson et al., 2003). Post-mortem weight loss is of particular interest to aquaculture as it represents a direct economic loss for the fishery industry (Jørpeland et al., 2013).

Among the species of fish farmed worldwide, tilapia farming, including Nile tilapia and some other cichlid species, is the most widespread type of aquaculture in the world (FAO, 2014). In Brazil, Nile tilapia (Oreochromis niloticus) is the most widely cultivated species with a production of 198.49 thousand tons in 2014 (IBGE, 2014).

Transportation of live fish from the farm to the processing unit is known to cause stress to the fish and leads to a number of physiological responses (Tacchi et al., 2015). In the industry, the arrival of live fish is important so that processing can occur during the period of pre-rigor mortis; fish processed during rigor mortis have impaired flesh quality (Bagni et al., 2007) and lower fillet yield (Erikson et al., 1997). Therefore, the study of pre-slaughter stress during the transportation of live fish to the processing unit is important to the provision of strategies to the aquaculture industry for improving fish handling techniques.

The aim of this study was to evaluate the stress caused by transportation at different stocking densities, different transportation times and the influence of these factors on stress, sensory characteristics and the quality of Nile tilapia fillets. 


\section{Materials and Methods}

The experiments were conducted in accordance with the guidelines of the Brazilian College for Animal Experimentation (COBEA) and approved by the Ethics Committee on the Use of Animals in Research (CEAE) of the State University of Maringá, Maringá, Paraná, Brazil (Protocol 010/2013-CEAE).

\section{Animals}

Fish were reared in net cages located in the Corvo River, in the municipality of Diamante do Norte, in the state of Paraná $\left(22^{\circ} 66^{\prime} \mathrm{S} ; 52^{\circ} 78^{\prime} \mathrm{W} ; 255 \mathrm{~m}\right)$. Net cages were stocked with 1,600 juveniles of Nile tilapia, TILAMAX variety, which were sexually reversed introducing masculinizing hormone 17- $\alpha$-methyltestosterone into the feed at the larval stage. Animals with $69.75 \pm 9.92 \mathrm{~g}$ average weight were placed at the initial average density of $9.3 \mathrm{~kg} \mathrm{~m}^{-3}$ in net cages, each of which had a capacity of 6 $\mathrm{m}^{3}(2.0 \times 2.0 \times 1.5 \mathrm{~m})$.

Fish were fed three times a day with a commercial diet containing $32 \%$ crude protein and $3500 \mathrm{kcal} \mathrm{kg}^{-1}$ of digestible energy for 210 days. Prior to transportation, the fish $(866.86 \pm 143.98 \mathrm{~g}$ average weight and $33.80 \pm$ $1.63 \mathrm{~cm}$ total length) were fasted for $24 \mathrm{~h}$ to empty the digestive tract.

\section{Experimental design}

To simulate different pre-slaughter handling situations with possible distinctions between levels of antemortem acute stress in individual tilapia, two experiments were conducted to examine different transportation times (Experiment 1) and stocking densities (Experiment 2), simulating the post-harvest transportation of live fish to the meat packing plant. Ten fish were sampled per treatment according to the following design:

Experiment 1: Two transportation times /60 and 240 min), with a density of $200 \mathrm{~kg} \mathrm{~m}^{-3}$, were compared with control treatment fish (which were removed from the net cage and immediately euthanized);

Experiment 2: Two transportation densities (100 and $400 \mathrm{~kg} \mathrm{~m}^{-3}$ ), with transportation for $180 \mathrm{~min}$, were compared with control treatment fish (in which the fish were removed from the net cage and immediately euthanized).

\section{Transportation characteristics}

Three boxes for the transportation of live fish were made of glass fiber with a capacity of $1000 \mathrm{~L}$ and equipped with diffusers and oxygen cylinders. The three boxes were placed in a fish transportation truck. To perform the experiment as close to the reality of the industry as possible, $6 \mathrm{~g} \mathrm{~L}^{-1}$ of sodium chloride were added to the water used for fish transportation (Oliveira et al., 2009).

Initially, fish were randomly taken from the net cages with the aid of a dip net, weighed on a portable scale and then placed in the three transportation boxes, each of which was stocked with a different density $(100$, 200 and $400 \mathrm{~kg} \mathrm{~m}^{-3}$ ).

The fish were then transported for 60,180 or 240 min using local roads at speeds simulating transportation between the collection site and the processing unit 150 $\left.\mathrm{km} \mathrm{h}^{-1}\right)$. The transportation times $(60,180$, and $240 \mathrm{~min})$ were coordinated with the arrival of the trucks at the processing unit.

Temperature and dissolved oxygen during transportation were monitored using a portable meter, maintaining an average temperature of $25.44 \pm 1.29{ }^{\circ} \mathrm{C}$ and an average dissolved oxygen rate of $8.05 \pm 3.19 \mathrm{mg} \mathrm{L}^{-1}$.

\section{Sampling}

Samples were collected when the truck arrived at the processing unit. Each sampling lasted approximately 5 min, during which time the transportation vehicle remained parked.

After taking the fish from the transportation box, blood was collected using tail puncture for analyzing glucose and cortisol. Subsequently, the fish were sacrificed by sectioning the spinal cord, submersing in ice water and subjecting to the ventral opening of the abdominal cavity from the urogenital opening to the branchial chamber, followed by the careful removal of the viscera to avoid contamination of the meat with faeces. The fish were beheaded, skinned and filleted by hand. The whole skinless fillets were washed in chlorinated water at $5 \mathrm{ppm}$, packed, placed in an insulated box with ice $\left(1 \pm 1^{\circ} \mathrm{C}\right)$ and transported to the laboratory for meat quality analyses.

\section{Stress indicators: glucose and cortisol}

Five fish from each treatment were subjected to blood collection by caudal vein puncture with the aid of disposable syringes; $1 \mathrm{~mL}$ blood was used for the plasma glucose analysis and $2 \mathrm{~mL}$ of blood for serum cortisol analysis. To separate the plasma, a $1 \mathrm{~mL}$ aliquot was poured into a tube containing fluoride EDTA, and centrifuged for $10 \mathrm{~min}$ at 2,500 rpm. Next, the supernatant was collected, corresponding to the plasma. Serum was obtained after submerging the blood samples in a water bath at $37^{\circ} \mathrm{C}$ for $10 \mathrm{~min}$, followed by centrifugation at 2,500 rpm for 10 min and collection of the supernatant (serum).

To evaluate plasma glucose levels, we used the glucose test based on the enzymatic photometric method according to the manufacturer's instructions. The analysis of the serum cortisol level was conducted using microparticle chemiluminescence immunoassay (CMIA) with the Architect 8200 system and a reagent kit of the same brand.

\footnotetext{
Analysis of $\mathrm{pH}$, color, water loss and water-holding capacity

The meat quality indicators evaluated were $\mathrm{pH}$, color, water-holding capacity (WHC), water loss by pressure and water loss during cooking. Analyses of $\mathrm{pH}$, color, water loss by pressure and water loss during cooking were performed in chilled samples, while the WHC was
} 
determined using frozen fillets. The fillets used for WHC analysis were frozen in a freezer at $-20^{\circ} \mathrm{C}$ for 5 days until analysis.

At $36 \mathrm{~h}$ post-mortem, the $\mathrm{pH}$ was measured in triplicate for each of the ten fillets in each treatment group using a portable digital potentiometer, which was equipped with a muscle electrode that was directly inserted into the fillets at three different points (dorsal, central and ventral parts).

At $36 \mathrm{~h}$ post-mortem, measurements of lightness were carried out in ten fillets per treatment on the ventral side of the fillet at six different reading points per sample. The values of lightness $\left(\mathrm{L}^{*}\right)$ were measured using a colorimeter at an angle of $90^{\circ}$ at room temperature, where $\mathrm{L}^{*}$ indicates the lightness $\left(\mathrm{L}^{*}=0\right.$ black and $\mathrm{L}^{*}=100$ white) and $b^{*}$ is the yellow-blue component.

Analysis of the water holding capacity (WHC) was performed on ten fillets per treatment as proposed by Lankhmanan et al. (2007). We used an analytical balance to weigh $1 \mathrm{~g}$ samples of raw muscle, in triplicate, placed in $1.5 \mathrm{~mL}$ tubes fitted with filter paper. The tubes were centrifuged at $1318 \times \mathrm{g}$ for $4 \mathrm{~min}$ at $4{ }^{\circ} \mathrm{C}$ in an Eppendorf centrifuge. Samples were weighed after centrifugation and dried in an oven at $70{ }^{\circ} \mathrm{C}$ for $12 \mathrm{~h}$. At the end of this period, the dried samples were weighed again. To calculate the WHC, we used the following formula:

$$
W H C \%=\frac{P C S W-D S W}{I S W} \times 100
$$

where: WHC\% = water-holding capacity, ISW = initial sample weight, PCSW = post-centrifugation sample weight, and DSW = dry sample weight.

The water loss by pressure was determined in triplicate in five fillets per treatment according to Stadnik et al. (2008). To measure water loss by pressure, 0.5 g muscle samples were placed between two qualitative filter paper circles $5.5 \mathrm{~cm}$ in diameter, $205 \mu \mathrm{m}$ in thickness and $80 \mathrm{~g} \mathrm{~m}^{-2}$ in weight placed between two square plates of glass $8 \mathrm{~mm}$ in thickness. Uniform pressure was applied to this assembly using a $10 \mathrm{~kg}$ weight for $5 \mathrm{~min}$. Then the samples were weighed again and the difference between the initial and final weights was expressed as a percentage.

Water loss during cooking was determined according to Cason et al. (1997) in ten fillets per treatment. We weighed $70.0 \mathrm{~g}$ of muscle on a semi-analytical balance, placed the samples in plastic bags and cooked them in a water bath until the internal temperature reached 75 $80{ }^{\circ} \mathrm{C}$ as monitored with a digital thermometer. Then, the samples were cooled to $30{ }^{\circ} \mathrm{C}$ and weighed again. The difference between the initial and final weights of the muscle was expressed as a percentage indicating the water loss during cooking.

\section{Sensory analysis}

For each experiment, we used two tests (acceptance and purchase intent). The tests were performed in accordance with Dutcosky (2007) using 90 untrained panellists selected at random. The judges' panel was composed of $43 \%$ women and $57 \%$ men; of the total panel, $17 \%$ were aged 17-26 years, $13 \%$ 27-36 years, $33 \%$ 37-46 years, $23 \%$ 47-56 years and $14 \%$ 57-60 years.

To evaluate the sensory acceptance of the fillets, they were initially thawed under refrigeration. The inclusion of salt in the fillets was made by submerging the fillets in brine with a dose of $10 \%$ common salt for 3 $\mathrm{min}$. The fillets were then cut into cubes of approximately $4 \mathrm{~g}$ and grilled on an electric grill with approximately $2 \mathrm{~mL}$ of soybean oil per $100 \mathrm{~g}$ meat. One fillet cube of each treatment was offered to each judge, and the different samples were identified with three random numbers using disposable materials free of extraneous odor. Along with the sensory analysis form, we offered a glass of water and a salt biscuit, and the judges were instructed to eat a piece of biscuit and drink water between samples.

The panellists were asked to rate the appearance, color, tenderness, juiciness and characteristic taste of the fish using a 9-point hedonic scale ranging from extreme dislike (1) to extreme like (9) (Dutcosky, 2007). Using these data we calculated the acceptability index (AI) of the products using the following equation (Dutcosky, 2007):

$$
A I \%=\frac{\text { average score of the product }}{9} \times 100(2)
$$

Additionally, the judges were asked to rate their purchase intent using a 5-point hedonic scale from 1 (definitely would not buy) to 5 (definitely would buy) in accordance with Dutcosky (2007).

\section{Statistical analysis}

The results, which are presented as the mean \pm standard error of the mean, were obtained from the analyses of five fish for glucose, cortisol and water loss by pressure, and from the analyses of ten fish for $\mathrm{pH}$, color, water-holding capacity and water loss during cooking.

Data obtained in the analyses for glucose, cortisol and meat quality were subjected to analysis of variance using the GLM procedure of the Statistical Analysis System v. 8.0; wherever significant differences $(p<0.05)$ were observed, Tukey's test was applied for the purpose of comparison between treatments.

For the statistical analysis of the sensory analysis results, we used the methodology of the generalized linear models (GENMOD procedure from SAS); we used the gamma distribution for the following variables: color, tenderness, juiciness, characteristic taste of the fish and purchase intent; and we used the normal distribution for the acceptability index. For these analyses, the following contrasts were proposed:

$$
\begin{aligned}
& \left.\mathrm{C}=\mu_{60 \mathrm{~min}}+\mu_{240 \mathrm{~min} 2}-2 \mu_{\text {control. }} \text { (sensory analysis } 1\right) \\
& \mathrm{C}=\mu_{100 \mathrm{~kg} \mathrm{~m}^{-3}}+\mu_{400 \mathrm{~kg} \mathrm{~m}^{-3}}-2 \mu_{\text {control. }} \text { (sensory analysis 2) }
\end{aligned}
$$

The contrasts were tested using t-tests at a $5 \%$ significance level. 


\section{Results}

\section{Experiment 1: Nile tilapia subjected to different transportation times}

The levels of serum cortisol (Figure 1A) and plasma glucose (Figure 1B) were significantly different between transportation times 60 and $240 \mathrm{~min}$; at $60 \mathrm{~min}$, tilapia showed higher levels of cortisol $(p=$ $0.0186)$ and glucose $(p=0.0031)$. At $240 \mathrm{~min}$, cortisol and glucose levels were similar to the control treatment.

Regarding the quality attributes of the evaluated fillets (Table 1), there were no differences $(p>0.05)$ between the treatments as regards $\mathrm{pH}$, lightness $\left(\mathrm{L}^{*}\right)$, chroma $b^{*}$ or water loss during cooking.

However, when evaluating water-holding capacity (WHC) and water loss by pressure, $60 \mathrm{~min}$ of transportation resulted in fillets with lower WHC ( $p$ $=0.0067$ ) (Figure 1A) and higher water loss by pressure $(p=0.0005)$ (Figure $2 \mathrm{~B})$ compared to the $240 \mathrm{~min}$ group. Fillets had a higher WHC $(60 \%)$ lower water loss by pressure $(30 \%)$ when transported for $240 \mathrm{~min}$. The times of 60 and $240 \mathrm{~min}$ did not differ from the control treatment for these parameters.

In the sensory analysis, there were no differences $(p>0.05)$ for the following characteristics: color, tenderness, characteristic taste of fish, acceptability index or purchase intent (Table 2). However, fish fillets transported for $240 \mathrm{~min}$ showed a higher level of juiciness (7.25) compared to the control fish (6.90).

\section{Experiment 2: Nile tilapia subjected to different transportation densities}

Fish subjected to different transportation densities (100 and $400 \mathrm{~kg} \mathrm{~m}^{-3}$ ) after $180 \mathrm{~min}$ of transportation showed no difference $(p=0.5186)$ in terms of serum cortisol levels; there was also no difference between the densities and the control treatment (Figure $3 \mathrm{~A})$. For plasma glucose, the densities of 100 and 400 $\mathrm{kg} \mathrm{m}^{-3}$ exhibited similar mean values, both of which were higher than the control mean $(p=0.0149)$ (Figure $3 \mathrm{~B})$.

With respect to the quality characteristics, the $\mathrm{pH}$ was different between the treatments; the density of $400 \mathrm{~kg} \mathrm{~m}^{-3}$ resulted in fillets with a higher $\mathrm{pH}$ (6.20) compared to the control (5.85) (Table 3). The mean $\mathrm{pH}$ of fillets at the density of $100 \mathrm{~kg} \mathrm{~m}^{-3}$ was similar to the other treatments (6.04). There were no differences $(p>0.05)$ between the treatments for lightness $\left(\mathrm{L}^{*}\right)$, chroma $\mathrm{b}^{*}$, water-holding capacity, water loss by pressure or water loss during cooking (Table 3).

With respect to the sensory evaluation of the fillets, there were no differences $(p>0.05)$ between treatments in terms of tenderness, juiciness, characteristic taste of fish or purchase intent (Table 4). However, the color of the fillets transported at the density of $400 \mathrm{~kg} \mathrm{~m}^{-3}$ reached a higher score $(7.39)$ compared to the control treatment fillets $(7.02)(p=0.0353)$. As a result, the acceptability index for fillets at a density of $400 \mathrm{~kg} \mathrm{~m}^{-3}$ was also higher than the other treatments $(81 \%)(p=0.0237)$.
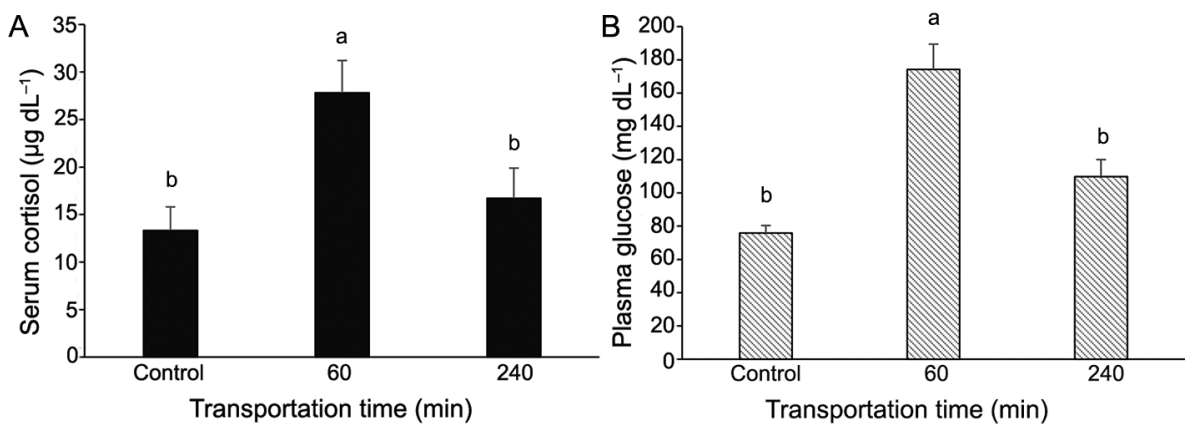

Figure 1 - Serum cortisol (A) and plasma glucose (B) of Nile tilapia transported at a density of $200 \mathrm{~kg} \mathrm{~m}^{-3}$ for 60 or 240 min. Different letters indicate significant differences between treatments according to Tukey's test $(p<0.05)$. Vertical lines represent the standard error of the mean $(n=5)$.

Table 1 - Quality attributes of Nile tilapia fillets transported at a density of $200 \mathrm{~kg} \mathrm{~m}^{-3}$ for 60 or $240 \mathrm{~min}$.

\begin{tabular}{|c|c|c|c|c|}
\hline \multirow{2}{*}{ Parameters } & \multirow{2}{*}{ Control } & \multicolumn{2}{|c|}{ Transportation time } & \multirow{2}{*}{$p$} \\
\hline & & 60 & 240 & \\
\hline & & 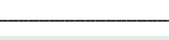 & 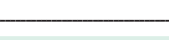 & \\
\hline $\mathrm{pH}$ & $5.85 \pm 0.12$ & $6.00 \pm 0.08$ & $6.11 \pm 0.06$ & 0.1781 \\
\hline$L^{*}$ & $45.08 \pm 0.51$ & $44.99 \pm 0.35$ & $43.87 \pm 0.42$ & 0.1080 \\
\hline$b^{*}$ & $8.16 \pm 0.21$ & $7.96 \pm 0.29$ & $7.55 \pm 0.23$ & 0.2178 \\
\hline Water loss during cooking (\%) & $22.91 \pm 0.79$ & $22.37 \pm 1.01$ & $20.90 \pm 0.91$ & 0.2831 \\
\hline
\end{tabular}

Data are expressed as the mean \pm standard error of the mean $(n=10) ; L^{*}=$ lightness ( 0 black and 100 white), $b^{*}$ (yellow-blue component). 


\section{Discussion}

The change in cortisol blood level is considered a primary response of organisms to stress; glucose, lactate and $\mathrm{pH}$ are usually secondary stress indicators (Ellis et al., 2012; Hultmann et al., 2012). In the present study, transportation for $60 \mathrm{~min}$ resulted in higher levels of serum cortisol and plasma glucose, and the levels of these metabolites found in the control treatment were re-established at $240 \mathrm{~min}$ of transportation (Figure $1 \mathrm{~A}$ and B), indicating a physiological adaptation of the animals to the transport conditions. Plasma levels of cortisol increase quickly after exposure to an acute stressor and the standard conditions are restored in a few hours (Poli, 2009; El-Khaldi, 2010), showing that Nile tilapia are highly adaptable to stressful situations. The different transportation densities (100 and
$400 \mathrm{~kg} \mathrm{~m}^{-3}$ ) did not affect the levels of cortisol and glucose, but the glucose levels in fish transported at these densities were higher than in the control treatment (Figure 3B). Although there was no difference in the primary indicator of stress (cortisol) between the different densities, the observed hyperglycemia is the body's response to stress because glucocorticoids, corticosteroids and catecholamines raise the level of blood sugar (Tejpal et al., 2009), which is also related to the release of hepatic glucose, the main reserve carbohydrate in fish (Enes et al., 2009).

Transport stress at different times (60 and $240 \mathrm{~min}$ ) affected the water-holding capacity (WHC) (Figure 2A) and the water loss by pressure (Figure 2B). The more stressed fish (transported for $60 \mathrm{~min}$ at the density of $200 \mathrm{~kg} \mathrm{~m}^{-3}$ ) showed lower WHC and greater water loss by pressure compared to fish transported for $240 \mathrm{~min}$.
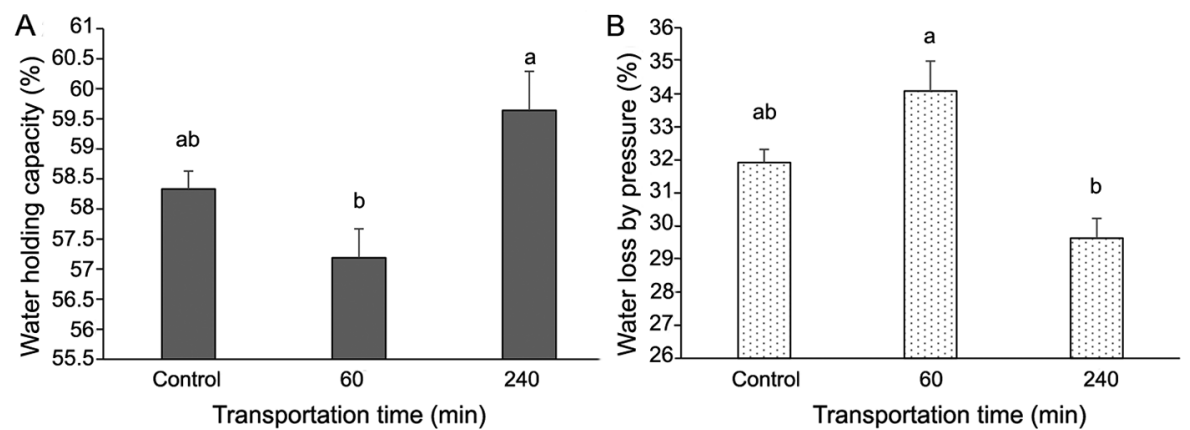

Figure 2 - Water-holding capacity (WHC) (A) and water loss by pressure (B) in Nile tilapia fillets transported at a density of $200 \mathrm{~kg} \mathrm{~m}^{-3}$ for 60 or $240 \mathrm{~min}$. Different letters indicate significant differences between treatments according to Tukey's test $(p<0.05)$. Vertical lines represent the standard error of the mean ( $n=10$ for WHC and $n=5$ for water loss by pressure).

Table 2 - Sensory attributes ${ }^{1}$, acceptability index and purchase intent ${ }^{2}$ for Nile tilapia fillets transported at a density of $200 \mathrm{~kg} \mathrm{~m}^{-3}$ for 60 or 240 min. $^{\circ}$

\begin{tabular}{|c|c|c|c|c|}
\hline \multirow{2}{*}{ Attributes } & \multirow{2}{*}{ Control } & \multicolumn{2}{|c|}{ Transportation time } & \multirow{2}{*}{ Contrast } \\
\hline & & 60 & 240 & \\
\hline Color & $7.02 \pm 0.15$ & $7.30 \pm 0.15$ & $7.11 \pm 0.15$ & 0.2331 \\
\hline Tenderness & $7.38 \pm 0.13$ & $7.34 \pm 0.15$ & $7.51 \pm 0.14$ & 0.4432 \\
\hline Juiciness & $6.90 \pm 0.15 b$ & $7.02 \pm 0.15 a b$ & $7.25 \pm 0.14 a$ & 0.0447 \\
\hline Characteristic taste of fish & $7.08 \pm 0.16$ & $7.03 \pm 0.17$ & $7.14 \pm 0.15$ & 0.8902 \\
\hline Acceptability index (\%) & $78.95 \pm 1.26$ & $79.94 \pm 1.39$ & $80.68 \pm 1.24$ & 0.2715 \\
\hline Purchase intent & $4.10 \pm 0.13$ & $4.18 \pm 0.11$ & $4.00 \pm 0.11$ & 0.4239 \\
\hline
\end{tabular}

${ }^{1}$ Hedonic scale between 1 (dislike extremely) and 9 (like extremely); ${ }^{2}$ Hedonic scale between 1 (definitely would not buy) and 5 (definitely would buy); Mean values in the same row followed by different letters are significantly different according to a t-test; Data are expressed as the mean \pm standard error of the mean $(n=90)$.

Table 3 - Quality characteristics of Nile tilapia fillets transported for $180 \mathrm{~min}$ at densities of 100 or $400 \mathrm{~kg} \mathrm{~m}^{-3}$.

\begin{tabular}{|c|c|c|c|c|}
\hline \multirow{2}{*}{ Parameters } & \multirow{2}{*}{ Control } & \multicolumn{2}{|c|}{ Transportation density } & \multirow{2}{*}{$p$} \\
\hline & & 100 & 400 & \\
\hline & & \multicolumn{2}{|c|}{$\mathrm{kg} \mathrm{m}^{-3}$} & \\
\hline $\mathrm{pH}$ & $5.85 \pm 0.12 b$ & $6.04 \pm 0.08 \mathrm{ab}$ & $6.20 \pm 0.06 a$ & 0.0458 \\
\hline$L^{*}$ & $45.08 \pm 0.51$ & $43.90 \pm 0.45$ & $45.32 \pm 0.65$ & 0.1587 \\
\hline$b^{*}$ & $8.16 \pm 0.21$ & $7.57 \pm 0.25$ & $7.83 \pm 0.32$ & 0.3040 \\
\hline Water-holding capacity (\%) & $58.33 \pm 0.30$ & $58.93 \pm 0.41$ & $59.10 \pm 0.38$ & 0.3134 \\
\hline Water loss by pressure (\%) & $31.92 \pm 0.40$ & $30.16 \pm 1.06$ & $31.76 \pm 0.77$ & 0.2526 \\
\hline Water loss during cooking (\%) & $22.91 \pm 0.79$ & $21.39 \pm 1.09$ & $20.80 \pm 1.20$ & 0.3493 \\
\hline
\end{tabular}

Mean values in the same row followed by different letters are significantly different according to Tukey's test $(p<0.05)$; Data are expressed as the mean \pm standard error of the mean $(n=10) ; L^{*}=$ lightness (0 black and 100 white), $b^{*}$ (yellow-blue component). 

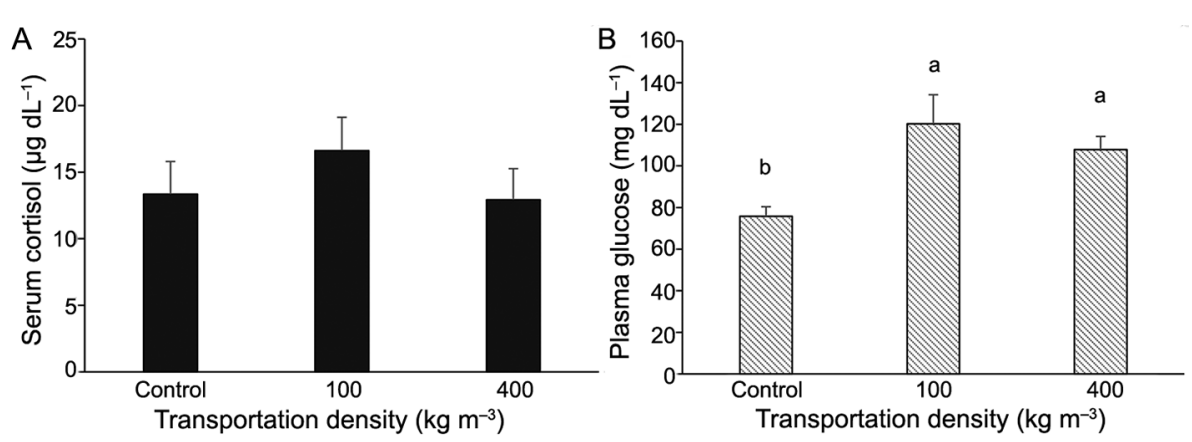

Figure 3 - Serum cortisol (A) and plasma glucose (B) of Nile tilapia transported for 180 min at densities of 100 and $400 \mathrm{~kg} \mathrm{~m}{ }^{-3}$. Different letters indicate significant differences between treatments according to Tukey's test $(p<0.05)$. Vertical lines represent the standard error of the mean $(n=5)$.

Table 4 - Sensory attributes ${ }^{1}$, acceptability index and purchase intent ${ }^{2}$ for Nile tilapia fillets transported for 180 min at densities of 100 or 400 $\mathrm{kg} \mathrm{m}^{-3}$.

\begin{tabular}{lccccc}
\hline \multirow{2}{*}{ Attributes } & \multirow{2}{*}{ Control } & \multicolumn{3}{c}{ Transportation density } & \multicolumn{2}{c}{ Contrast } \\
\cline { 3 - 5 } & & & 100 & & \\
\cline { 3 - 5 } Color & $7.02 \pm 0.15 \mathrm{~b}$ & $7.15 \pm 0.16 \mathrm{ab}$ & $7.39 \pm 0.14 \mathrm{a}$ & 0.0353 \\
Tenderness & $7.38 \pm 0.13$ & $7.38 \pm 0.16$ & $7.53 \pm 0.14$ & 0.5108 \\
Juiciness & $6.90 \pm 0.15$ & $6.90 \pm 0.15$ & $7.17 \pm 0.14$ & 0.1558 \\
Characteristic taste of fish & $7.08 \pm 0.16$ & $6.92 \pm 0.16$ & $7.19 \pm 0.16$ & 0.4142 \\
\hline Acceptability index (\%) & $78.95 \pm 1.26 \mathrm{~b}$ & $78.96 \pm 1.45 \mathrm{~b}$ & $81.45 \pm 1.29 \mathrm{a}$ & 0.0237 \\
\hline Purchase intent & $4.10 \pm 0.13$ & $3.98 \pm 0.11$ & $4.21 \pm 0.10$ & 0.1963 \\
\hline
\end{tabular}

${ }^{1}$ Hedonic scale between 1 and 9 ; ${ }^{2}$ Hedonic scale between 1 and 5 ; Mean values in the same row followed by different letters are significantly different according to a t-test; Data are expressed as the mean \pm standard error of the mean $(n=90)$.

Several studies have linked pre-slaughter stress with decreased WHC in fish (Bjørnevik and Solbakken, 2010; Digre et al., 2011; Hultmann et al., 2012; Goes et al., 2015). Water- (or liquid-) holding capacity (also called water-binding capacity) can be defined as the amount of water left after centrifugation relative to either the water present before centrifugation or to the dry weight (Andersen and Jørgensen, 2004). Methods that measure water retention in muscle refer to the amount of liquid retained in a protein system by the application of force according to the measurement conditions. No absolute figures exist since the amount of loose water depends on the type and amount of force applied (Jauregui et al., 1981). Various techniques have been used for the determination of WHC, such as drip loss (Honikel, 1998; Otto et al., 2004), filter paper wetness (Brøndum et al., 2000), cooking/heating loss (Aaslyng et al., 2003), the centrifuge force method (Zhang et al., 1995), thawing loss, processing loss, technological yield, etc. (Bertram et al., 2003; Prevolnik et al., 2010). Factors that influence WHC include the levels of lactic acid, inosine monophosphate, adenosine triphosphate (ATP), inosine, glycogen, $\mathrm{pH}$, and the temperature of the muscle (Schäfer et al., 2002). Lund et al. (2011) reported that the ability of the muscle to retain water is affected by several factors, such as $\mathrm{pH}$, post-mortem protein oxidation, proteolytic activity of the meat-tenderizing enzymes, and cross-linking of myofibrillar proteins. In particular, WHC is affected by $\mathrm{pH}$; the $\mathrm{pH}$ near the isoelectric point of proteins decreases the WHC (Huff-Lonergan and Lonergan, 2005). Nevertheless, in this study, it was not possible to connect changes in WHC to the $\mathrm{pH}$ of the muscle at $36 \mathrm{~h}$ post-mortem because there was no difference in $\mathrm{pH}$ for different transportation times (60 and $240 \mathrm{~min}$ ) (Table 1).

Differences in $\mathrm{pH}$ were found between fish subjected to different transportation densities, a higher density resulting in higher $\mathrm{pH}(6.20)$ compared to the control treatment (5.85) (Table 3). Slaughter immediately after harvesting may have caused a faster consumption of glycogen with an increasing anaerobic respiration rate, resulting in increased production of lactic acid which lowers the $\mathrm{pH}$ of the meat relative to the two fish densities (100 and $400 \mathrm{~kg} \mathrm{~m}^{-3}$ ), which had been transported for $180 \mathrm{~min}$ and possibly had time to restore glycogen rates. However, these changes in $\mathrm{pH}$ were not able to influence the other quality parameters of the meat (Table 3).

The greater water losses observed in the fillets of more stressed fish in this study affected the juiciness of the meat, corroborating previous studies by Huff-Lonergan and Lonergan (2005). In the sensory analysis, the fillets that were transported for $240 \mathrm{~min}$ had higher WHC, less water loss by pressure, and better scores for juiciness. For the consumer, a higher water-holding capacity brings the sensation of juiciness during chewing (Desmond, 2006), which is corroborated by the results of this study. 
Despite the lack of differences in the values of lightness $\left(\mathrm{L}^{*}\right)$ and chroma $\mathrm{b}^{*}$ between fillets transported at different densities (100 and $\left.400 \mathrm{~kg} \mathrm{~m}^{-3}\right)$, fish transported at $400 \mathrm{~kg} \mathrm{~m}^{-3}$ showed better scores for the attribute of color and higher scores on the sensory acceptability index (Table 4). However, as there were no differences between the stress indicators and meat quality parameters between the two densities, it was not possible to connect the results obtained in the sensory analysis with the other results. The sensory evaluation of Atlantic cod (Gadus morhua) fillets showed that fish slaughtered with anesthetic showed a brighter surface color than the fillets of fish exposed to pre-slaughter stress, but the tasters did not notice differences in odor, flavor nor texture (Digre et al., 2011). Meanwhile, differences in the fillet texture of cod slaughtered with and without ante-mortem stress were observed by trained tasters (Sveinsdóttir et al., 2010).

The sensory attributes evaluated in both sensory analyses showed values between 6.90 and 7.53 for the characteristics of color, tenderness, juiciness and the characteristic taste of the fish. Considering that on the hedonic scale, the values 6 and 8 correspond to "like slightly" and "like very much", respectively, these results indicate a favorable attitude toward Nile tilapia by the judges, a fact corroborated by the acceptability indices above $70 \%$ [Dutcosky (2007) recommended a minimum acceptability index of $70 \%$ for the product to be well accepted]. Moreover, the value observed for purchase intent was 3.98. Because the score 4 represented the choice "would possibly buy", this result suggests that the tasters would probably show interest in buying the Nile tilapia fillets.

\section{Conclusions}

Fish with lower levels of serum cortisol and plasma glucose (subjected to 240 min of transportation at a density of $200 \mathrm{~kg} \mathrm{~m}^{-3}$ ) had meat with a greater waterholding capacity, less water loss by pressure and greater juiciness compared to fish with increased levels of serum cortisol and plasma glucose (subjected to 60 min of transportation at a density of $200 \mathrm{~kg} \mathrm{~m}^{-3}$ ). Transportation densities of 100 and $400 \mathrm{~kg} \mathrm{~m}^{-3}$ at $180 \mathrm{~min}$ of transportation showed no influence on the stress indicators and instrumental quality parameters of the fillets, but fish transported at $400 \mathrm{~kg} \mathrm{~m}^{-3}$ showed better visual acceptance by panellists.

The results demonstrate that lower pre-slaughter stress of Nile tilapia can reduce the water loss of fillets, an important factor in the avoidance of economic losses due to weight loss and the sensory quality of fillets in the fish processing industry.

\section{References}

Aaslyng, M.D.; Bejerholm, C.; Ertbjerg, P.; Bertram, H.C.; Andersen, H.J. 2003. Cooking loss and juiciness of pork in relation to raw meat quality and cooking procedure. Food Quality and Preference 14: 277-288.
Andersen, C.M.; Jørgensen, B.M. 2004. On the relation between water pools and water holding capacity in cod muscle. Journal of Aquatic Food Product Technology 13: 13-23

Bagni, M.; Civitareale, C.; Priori, A.; Ballerini, A.; Finoia, M.; Brambilla, G.; Marino, G. 2007. Pre-slaughter crowding stress and killing procedures affecting quality and welfare in sea bass (Dicentrarchus labrax) and sea bream (Sparus aurata). Aquaculture 263: 52-60.

Bahuaud, D.; Mørkøre, T.; Østbye, T.K.; Veiseth-Kent, E.; Thomassen, M.S.; Ofstad, R. 2010. Muscle structure responses and lysosomal cathepsins $\mathrm{B}$ and $\mathrm{L}$ in farmed Atlantic salmon (Salmo salar L.) pre-and post-rigor fillets exposed to short and long-term crowding stress. Food Chemistry 118: 602-615.

Barton, B.A. 2002. Stress in fishes: a diversity of responses with particular reference to changes in circulating corticosteroids. Integrative and Comparative Biology 42: 517-525.

Bertram, H.C.; Andersen, H.J.; Karlsson, A.H.; Horn, P.; Hedegaard, J.; Nørgaard, L.; Engelsen, S.B. 2003. Prediction of technological quality (cooking loss and Napole Yield) of pork based on fresh meat characteristics. Meat Science 65: 707-712.

Bjørnevik, M.; Solbakken, V. 2010. Preslaughter stress and subsequent effect on flesh quality in farmed cod. Aquaculture Research 41: e467-e474.

Brøndum, J.; Munck, L.; Henckel, P.; Karlsson, A.; Tornberg, E.; Engelsen, S.B. 2000. Prediction of water-holding capacity and composition of porcine meat by comparative spectroscopy. Meat Science 55: 177-185.

Cason, J.A.; Lyon, C.E.; Papa, C.M. 1997. Effect of muscle opposition during rigor on development of broiler breast meat tenderness. Poultry Science 76: 725-787.

Desmond, E. 2006. Reducing salt: a challenge for the meat industry. Meat Science 74: 188-196.

Digre, H.; Erikson, U.; Skaret, J.; Lea, P.; Gallart-Jornet, L.; Misimi, E. 2011. Biochemical, physical and sensory quality of ice-stored Atlantic cod (Gadus morhua) as affected by pre-slaughter stress, percussion stunning and AQUI-S ${ }^{\mathrm{TM}}$ anaesthesia. European Food Research and Technology 233: 447-456.

Dutcosky, S.D. 2007. Sensory Analysis of Food = Análise Sensorial de Alimentos. 2ed. Editora Champagnat, Curitiba, PR, Brazil (in Portuguese).

El-Khaldi, A.T. 2010. Effect of different stress factors on some physiological parameters of Nile tilapia (Oreochromis niloticus). Saudi Journal of Biological Sciences 17: 241-246.

Ellis, T.; Yildiz, H.Y.; López-Olmeda, J.; Spedicato, M.T.; Tort, L.; Øverli, Ø.; Martins, C.I. 2012. Cortisol and finfish welfare. Fish Physiology and Biochemistry 38: 163-188.

Enes, P.; Panserat, S.; Kaushik, S.; Oliva-Teles, A. 2009. Nutritional regulation of hepatic glucose metabolism in fish. Fish Physiology and Biochemistry 35: 519-539.

Erikson, U.; Sigholt, T.; Seland, A. 1997. Handling stress and water quality during live transportation and slaughter of Atlantic salmon (Salmo salar). Aquaculture 149: 243-252.

Food and Agriculture Organization of the United Nations [FAO]. 2014. The State of World Fisheries and Aquaculture 2014. FAO-Fisheries and Aquaculture Department, Rome, Italy. 
Goes, E.S.R.; Lara, J.A.F.; Gasparino, E.; Del Vesco, A.P.; Goes, M.D.; Alexandre Filho, L.; Ribeiro, R.P. 2015. Pre-slaughter stress affects ryanodine receptor protein gene expression and the water-holding capacity in fillets of the Nile tilapia. Plos One 10: e0129145.

Honikel, K.O. 1998. Reference methods for the assessment of physical characteristics of meat. Meat Science 49: 447-457.

Huff-Lonergan, E.; Lonergan, S.M. 2005. Mechanisms of waterholding capacity of meat: the role of postmortem biochemical and structural changes. Meat Science 71: 194-204.

Hultmann, L.; Phu, T.M.; Tobiassen, T.; Aas-Hansen, Ø.; Rustad, T. 2012. Effects of pre-slaughter stress on proteolytic enzyme activities and muscle quality of farmed Atlantic cod (Gadus morhua). Food Chemistry 134: 1399-1408.

Instituto Brasileiro de Geografia e Estatística [IBGE]. 2014. Municipal Livestock Production = Produção da Pecuária Municipal. IBGE, Rio de Janeiro, RJ, Brazil (in Portuguese).

Jauregui, C.A.; Regenstein, J.M.; Baker, R.C. 1981. A simple centrifugal method for measuring expressible moisture, a water-binding property of muscle foods. Journal of Food Science 46: 1271-1273.

Jørpeland, G.; Imsland, A.; Stien, L.H.; Bleie, H.; Roth, B. 2013. Effects of filleting method, stress, storage and season on the quality of farmed Atlantic cod (Gadus morhua L.). Aquaculture Research 46: 1-11.

Lankhmanan, R.; Parkinson, J.A.; Piggott, J.R. 2007. Highpressure processing and water holding capacity of fresh and cold-smoked salmon (Salmo salar). LWT - Food Science and Technology 40: 544-551.

Lund, M.N.; Heinonen, M.; Baron, C.P.; Estévez, M. 2011. Protein oxidation in muscle foods: a review. Molecular Nutrition \& Food Research 55: 83-95.

Oliveira, J.R.; Carmo, J.L.; Oliveira, K.K.C.; Soares, M.C.F. 2009. Sodium chloride, benzocaine and clove oil in tilapia transport water. Revista Brasileira de Zootecnia, 38: 1163-1169 (in Portuguese, with abstract in English).

Olsson, G.B.; Olsen, R.L.; Ofstad, R. 2003. Post-mortem structural characteristics and water-holding capacity in Atlantic halibut muscle. LWT - Food Science and Technology 36: 125-133.

Otto, G.; Roehe, R.; Looft, H.; Thoelking, L.; Kalm, E. 2004. Comparison of different methods for determination of drip loss and their relationships to meat quality and carcass characteristics in pigs. Meat Science 68: 401-409.

Poli, B.M. 2009. Farmed fish welfare-suffering assessment and impact on product quality. Italian Journal of Animal Science 8: 139-160.

Prevolnik, M.; Čandek-Potokar, M.; Škorjanc, D. 2010. Predicting pork water-holding capacity with NIR spectroscopy in relation to different reference methods. Journal of Food Engineering 98: 347-352.
Rahmanifarah, K.; Shabanpour, B.; Sattari, A. 2011. Effects of clove oil on behavior and flesh quality of common carp (Cyprinus carpio L.) in comparison with pre-slaughter $\mathrm{CO}_{2}$ stunning, chilling and asphyxia. Turkish Journal of Fisheries and Aquatic Sciences 11: 139-147.

Roth, B.; Slinde, E.; Arildsen, J. 2006. Pre or post mortem muscle activity in Atlantic salmon (Salmo salar). The effect on rigor mortis and the physical properties of flesh. Aquaculture 257: 504-510.

Roth, B.; Grimsbø, E.; Slinde, E.; Foss, A.; Stien, L.H.; Nortvedt, R. 2012. Crowding, pumping and stunning of Atlantic salmon, the subsequent effect on $\mathrm{pH}$ and rigor mortis. Aquaculture 326-329: 178-180.

Schäfer, A.; Rosenvold, K.; Purslow, P.P.; Andersen, H.J.; Henckel, P. 2002. Physiological and structural events post mortem of importance for drip loss in pork. Meat Science 61: 355-366.

Stadnik, J.; Dolatowski, Z.J.; Baranowska, H.M. 2008. Effect of ultrasound treatment on water holding properties and microstructure of beef ( $m$. semimembranosus $)$ during ageing. LWT - Food Science and Technology 41: 2151-2158.

Stien, L.H.; Hirmas, E.; Bjørnevik, M.; Karlsen, Ø.; Nortvedt, R.; Rørå, A.M.B.; Sunde, J.; Kiessling, A. 2005. The effects of stress and storage temperature on the colour and texture of pre-rigor filleted farmed cod (Gadus morhua L.). Aquaculture Research 36: 1197-1206.

Sveinsdóttir, K.; Martinsdóttir, E.; Thórsdóttir, F.; Schelvis, R.; Kole, A.; Thórsdóttir, I. 2010. Evaluation of farmed cod products by a trained sensory panel and consumers in different test settings. Journal of Sensory Studies 25: 280-293.

Tacchi, L.; Lowrey, L.; Musharrafieh, R.; Crossey, K.; Larragoite, E.T.; Salinas, I. 2015. Effects of transportation stress and addition of salt to transport water on the skin mucosal homeostasis of rainbow trout (Oncorhynchus mykiss). Aquaculture 435: 120127.

Tejpal, C.S.; Pal, A.K.; Sahu, N.P.; Kumar, J.A.; Muthappa, N.A.; Vidya, S.; Rajan, M.G. 2009. Dietary supplementation of L-tryptophan mitigates crowding stress and augments the growth in Cirrhinus mrigala fingerlings. Aquaculture 293: 272277.

Zhang, M.; Mittal, G.S.; Barbut, S. 1995. Effects of test conditions on the water holding capacity of meat by a centrifugal method. LWT-Food Science and Technology 28: 50-55. 